\title{
Preparation, Characterization and Application of Sulphuric Acid-Treated Soursop (Annona muricata L.) Seeds Powder in the Adsorption of $\mathrm{Cu}(\mathrm{II})$ lons
}

\author{
Megat Ahmad Kamal Megat Hanafiah*, Nurul Amira Abu Bakar*, Waheeba A. Al-Amrani**, \\ Shariff Ibrahim***†, Nik Ahmad Nizam Nik Malek**** and Ali H. Jawad*** \\ *Faculty of Applied Sciences, Universiti Teknologi MARA, 26400, Jengka, Pahang, Malaysia \\ **Department of Chemistry, Faculty of Science, Ibb University, Ibb, Yemen \\ ***Faculty of Applied Sciences, Universiti Teknologi MARA, 40450, Shah Alam, Selangor, Malaysia \\ *****Department of Biosciences, Faculty of Science, Universiti Teknologi Malaysia, 81310, Skudai, Johor, Malaysia \\ $†$ Corresponding author: Shariff Ibrahim; sha88@uitm.edu.my
}

\section{Nat. Env. \& Poll. Tech. \\ Website: www.neptjournal.com \\ Received: 12-02-2021 \\ Revised: 25-05-2021 \\ Accepted: 07-06-2021 \\ Key Words: \\ Adsorption \\ Annona muricata \\ Copper \\ Isotherm \\ Kinetics}

\begin{abstract}
This work presented the adsorption of $\mathrm{Cu}$ (II) ions using agriculture waste coming from soursop (Annona muricata L.) seeds. The chemical treatment performed on Annona muricata L. seeds was carried out using $1.0 \mathrm{M} \mathrm{H}_{2} \mathrm{SO}_{4}$ solutions. The Fourier-transform infrared (FTIR) spectrophotometer, scanning electron microscope coupled with energy dispersive X-ray (SEM-EDX), $\mathrm{pH}$ of point-zero-charge $\left(\mathrm{pH}_{\mathrm{PZC}}\right)$, and $\mathrm{pH}_{\text {slurry }}$ analyses were done to characterize the surface properties of the adsorbent. Experimental conditions such as contact time, adsorbent dosage, $\mathrm{pH}$, and initial $\mathrm{Cu}(\mathrm{II})$ ion concentrations, all of which could affect $\mathrm{Cu}(\mathrm{II})$ ions adsorption, were studied. The adsorption kinetics was successfully described by the pseudo-second-order model. The Langmuir and Freundlich models were applied to interpret the $\mathrm{Cu}$ (II) ions' adsorption at equilibrium. The isotherm data fitted well with the Freundlich model and the maximum adsorption capacity was $187.83 \mathrm{mg} . \mathrm{g}^{-1}$ based on the Langmuir model.
\end{abstract}

\section{INTRODUCTION}

The discharge of heavy metal ions into water bodies from different industrial effluents, such as metal plating, petrochemicals, batteries, chemicals, paints, and pesticide production has caused serious global environmental issues (Zafar et al. 2020). Heavy metal ions can enter the food chain, accumulate in the aquatic ecological system, and cause harmful effects on humans, plants, animals, and the environment (Afroze \& Sen 2018). Copper (Cu) at trace level is essential to human life. In tiny quantities, the metal is crucial in maintaining the health of an individual. In contrast, prolonged exposure to surplus $\mathrm{Cu}$ (II) ions causes serious illnesses to humans, such as kidney and liver damage, headaches, increased heart rate, and schizophrenia (Al Zabadi et al. 2018). The World Health Organization (WHO) and Environmental Protection Agency (EPA) have set the maximum allowable concentrations of 1.3 and $2.0 \mathrm{mg} . \mathrm{L}^{-1}$, respectively for $\mathrm{Cu}(\mathrm{II})$ ions in drinking water (Zafar et al. 2020). Therefore, it is crucial to remove $\mathrm{Cu}$ (II) ions from industrial effluents to avoid environmental catastrophe.

Numerous techniques have already been implemented to reduce $\mathrm{Cu}$ (II) ions concentration in aqueous solutions, including chemical precipitation, coagulation, adsorption, electrolysis, ultrafiltration, ion exchange, reverse osmosis, and advanced oxidation. Adsorption in particular is much preferred due to the high and fast removal efficiency, relatively low cost, and design simplicity (Karimi et al. 2019). Synthetic materials such as polymers have been developed as adsorbents for heavy metals removal. However, prolonged and extensive use of synthetic adsorbents will lead to secondary pollutants in the form of by-products (Wang et al. 2020). Therefore, the use of natural adsorbents derived from renewable biomaterials with a lower risk to the environment has gained more attention (Li et al. 2007, Wang et al. 2020).

Annona muricata $\mathrm{L}$. fruit or soursop has many functional groups such as -OH (hydroxyl), $-\mathrm{NH}_{2}$ (amino), - $\mathrm{COOH}$ (carboxylic acid), C-O-C (ether), and aromatic rings (Sawant \& Dongre 2014, Anaya Esparza \& Montalvo-González 2020), which play a dynamic role in the metal binding mechanisms. These functional groups originate from chemical components such as lignin, cellulose, hemicellulose, fatty acids, lipids, sugars, and proteins (Menzes et al. 2019). Untreated and chemically treated $A$. muricata $\mathrm{L}$. seeds have been used as an adsorbent to remove pollutants, such as Tartrazine dye (Fauzia et al. 2015), Rhodamine B dye (Cairdir et al. 2015), 
and heavy metal ions (Oboh \& Aluyor 2008, Kurniawan et al. 2014) from their aqueous solutions.

Oboh \& Aluyor (2008) studied the adsorption of four heavy metal ions using untreated $A$. muricata $\mathrm{L}$. seeds powder under batch mode. The removal efficiencies were 77.6, 68.5, 56.4, and $40.6 \%$ for $\mathrm{Cu}(\mathrm{II}), \mathrm{Ni}(\mathrm{II}), \mathrm{Zn}(\mathrm{II})$, and $\mathrm{Pb}(\mathrm{II})$ ions, respectively. Kurniawan et al. (2014) performed the removal of $\mathrm{Pb}(\mathrm{II})$ and $\mathrm{Cu}(\mathrm{II})$ ions using $\mathrm{HNO}_{3}$-treated A. muricata $\mathrm{L}$. seeds powder. The results showed that the maximum adsorption capacities for $\mathrm{Pb}$ (II) and $\mathrm{Cu}$ (II) ions were 5.58 and 4.16 $\mathrm{mg} . \mathrm{g}^{-1}$, respectively. Fauzia et al. (2015) reported a maximum adsorption capacity of $23.63 \mathrm{mg} \cdot \mathrm{g}^{-1}$ for Tartrazine dye using HCl-treated A. muricata L. seeds powder. Another study done by Cairdir et al. (2015) found the maximum adsorption capacity of $53.37 \mathrm{mg} \cdot \mathrm{g}^{-1}$ for Rhodamine B using HCl-treated A. muricata L. seeds powder. However, it could be noticed that the untreated, $\mathrm{HCl}$ and $\mathrm{HNO}_{3}$-treated $A$. muricata $\mathrm{L}$. seeds did not show a high adsorption capacity towards heavy metal ions and dyes. Therefore, there is a need to search for another acid treatment method that enhances the adsorption performance of $A$. muricata $\mathrm{L}$. seeds.

In this work, the applicability of A. muricata L. seeds powder treated with 1.0 M sulphuric acid solution as an adsorbent to remove $\mathrm{Cu}$ (II) ions from aqueous solutions has been investigated. Characterization of the surface of A. muricata L. seeds powder using the Fourier-transform infrared (FTIR) spectrophotometer, scanning electron microscope coupled with energy dispersive $\mathrm{X}$-ray (SEM$\mathrm{EDX}), \mathrm{pH}$ of point-zero-charge $\left(\mathrm{pH}_{\mathrm{PZC}}\right)$ and $\mathrm{pH}_{\text {slurry }}$ were performed. Furthermore, the physiochemical parameters such as contact time, $\mathrm{pH}$, adsorbent dosage, and the initial $\mathrm{Cu}$ (II) concentration were studied. The rate of adsorption and determination of maximum adsorption capacity of $A$. muricata L. seeds powder was determined using kinetics and isotherm models, respectively.

\section{MATERIALS AND METHODS}

A. muricata L. fruits were bought from an orchard in Temerloh, Malaysia. The fruits were cut and the black seeds were collected. The seeds were rinsed thoroughly with deionized water several times before being dried in an oven (Electro-thermal Blast Drying Oven, China) at $90^{\circ} \mathrm{C}$ overnight. After drying, the seeds were crushed using a mechanical crusher into a powdered form. To remove the fat, a pre-treatment was done by mixing $20 \mathrm{~g}$ of the powder with $200 \mathrm{~mL}$ of hexane (ratio of 1:10 (w/v) seeds powder to hexane) for $16 \mathrm{~h}$ at $28^{\circ} \mathrm{C}$. The hexane-treated powder was filtered and dried at $80^{\circ} \mathrm{C}$ for $3 \mathrm{~h}$ and was abbreviated as AMSP. The preparation of treated AMSP using sulphuric acid (98\% w/w; Loba Chemie, India) was performed to enhance the adsorption properties of AMSP. The dried AMSP was mixed with $100 \mathrm{~mL}$ (1.0 M $\mathrm{H}_{2} \mathrm{SO}_{4}$ ) for $2 \mathrm{~h}$, washed thoroughly with deionized water until the final $\mathrm{pH}$ reached near 7 . Finally, the powder was dried at $80^{\circ} \mathrm{C}$ overnight and was labeled SA-AMSP.

\section{Characterization}

The functional groups, surface properties and elemental composition of the AMSP and SA-AMSP, and the $\mathrm{Cu}$ (II) ions-loaded SA-AMSP were inspected using a Fourier-transform infrared (FTIR) spectrophotometer (PerkinElmer, Spectrum 100, USA) and a scanning electron microscope (SEM, Carl Zeiss SMT, Germany) coupled with energy dispersive $\mathrm{X}$-ray (EDX, Oxford Instrument, UK) spectrometer. The $\mathrm{pH}_{\text {slurry }}$ was determined by mixing $0.10 \mathrm{~g}$ of SA-AMSP with $50 \mathrm{~mL}$ of distilled water. The mixture was left for $24 \mathrm{~h}$ at $29^{\circ} \mathrm{C}$. The mixture was filtered using a Whatman filter paper (No. 42), and the final $\mathrm{pH}$ in the supernatant was measured using a $\mathrm{pH}$ meter. The $\mathrm{pH}_{\mathrm{PZC}}$ determination of SA-AMSP was performed as follows: firstly, a series of $50 \mathrm{~mL}(0.01 \mathrm{M})$ $\mathrm{NaCl}$ solutions at different initial $\mathrm{pH}\left(\mathrm{pH}_{\mathrm{i}}\right)$ of 2 to 10 were prepared in $100 \mathrm{~mL}$ conical flasks. Then, $0.10 \mathrm{~g}$ of SA-AMSP was added to the $\mathrm{NaCl}$ solutions, and the mixture was stirred using a magnetic stirrer for $24 \mathrm{~h}$. The mixture was filtered using a Whatman filter paper (No. 42), and the final $\mathrm{pH}$ of the solution $\left(\mathrm{pH}_{\mathrm{f}}\right)$ was recorded. The plot of $\mathrm{pH}_{\mathrm{i}}-\mathrm{pH}_{\mathrm{f}}$ versus $\mathrm{pH}_{\mathrm{i}}$ was constructed, and the curve that intercepted the $\mathrm{pH}_{\mathrm{i}}$ axis represented the $\mathrm{pH}_{\mathrm{PZC}}$ value of SA-AMSP.

\section{Batch Adsorption Process}

Batch adsorption experiments were performed in stoppered conical flasks, stirred using a magnetic stirrer (120 rpm) at $302 \mathrm{~K}$ for $120 \mathrm{~min}$, and the volume of $\mathrm{Cu}(\mathrm{II})$ ions was kept at $50 \mathrm{~mL}$. A stock solution of $\mathrm{Cu}(\mathrm{II})$ concentration $(1000$ mg. $\mathrm{L}^{-1}$ ) was prepared by dissolving the measured amount of copper nitrate salt, $\mathrm{Cu}\left(\mathrm{NO}_{3}\right)_{2} \cdot 3 \mathrm{H}_{2} \mathrm{O}$ (Merck, Germany) in deionized water. Then, the stock solution was diluted to prepare the required $\mathrm{Cu}(\mathrm{II})$ concentrations. The $\mathrm{pH}$ varied from 2 to 6 , and the SA-AMSP dosage changed from 0.02 to $0.10 \mathrm{~g}$ depending on the effects of $\mathrm{pH}$ and adsorbent dosage to adsorb $20 \mathrm{mg} . \mathrm{L}^{-1}$ of $\mathrm{Cu}$ (II) ions, respectively. Drops of 0.1 $\mathrm{M} \mathrm{NaOH}$ and $0.1 \mathrm{M} \mathrm{HCl}$ solutions were added to adjust the $\mathrm{pH}$ of the solutions using a pH meter (EUTECH Instruments, USA). Two different concentrations of 10 and $20 \mathrm{mg} . \mathrm{L}^{-1}$ were used in the kinetics study. The $\mathrm{Cu}(\mathrm{II})$ concentrations varied from 10 to $60 \mathrm{mg} . \mathrm{L}^{-1}$ in the isotherm study at $\mathrm{pH} 6$. The mixture was filtered using a Whatman filter paper (No. 42) and the residual concentration of $\mathrm{Cu}(\mathrm{II})$ ions was measured using an atomic absorption spectrophotometer (AAS, PerkinElmer, PinAAcle 900T model, USA). All adsorption experiments were done in duplicates, and the results were 
presented as the average. The removal of $\mathrm{Cu}$ (II) ions was calculated using the following equation:

$$
\% \text { Removal }=\frac{C_{o}-C_{e}}{C_{o}} \times 100
$$

where, $C_{o}$ and $C_{e}$ represent the $\mathrm{Cu}(\mathrm{II})$ concentration before and after adsorption (mg. $\left.\mathrm{L}^{-1}\right)$, respectively. The amount of $\mathrm{Cu}$ (II) ions adsorbed on SA-AMSP at equilibrium was calculated using the following equation:

$$
q_{e}=\frac{V\left(C_{o}-C_{e}\right)}{m}
$$

where $V$ is the volume of adsorbate $(\mathrm{L}), q_{e}$ is the amount of $\mathrm{Cu}(\mathrm{II})$ ions adsorbed $\left(\mathrm{mg} \cdot \mathrm{g}^{-1}\right)$ at equilibrium and $m$ is the weight of SA-AMSP (g). The non-linear trial-and-error methods were performed using the Solver add-in (Microsoft Excel) to calculate the parameters of adsorption kinetics and isotherm models. The chi-square $\left(\chi^{2}\right)$ test expressed in Eq. 3 and the regression coefficient $\left(R^{2}\right.$, Eq. 4) were used to compare the best fit of the kinetics and isotherm models:

$$
\begin{gathered}
\chi^{2}=\sum \frac{\left(q_{e}^{\text {exp }}-q_{e}^{c a l}\right)^{2}}{q_{e}^{c a l}} \\
R^{2}=1-\frac{\sum\left(q_{e}^{\text {exp }}-q_{e}^{\text {cal }}\right)^{2}}{\sum\left(q_{e}^{\text {exp }}-q_{e}^{\text {mean }}\right)^{2}}=\frac{\sum\left(q_{e}^{\text {exp }}-q_{e}^{\text {cal }}\right)^{2}}{\sum\left(q_{e}^{\text {cal }}-q_{e}^{\text {mean }}\right)^{2}+\sum\left(q_{e}^{\text {cal }}-q_{e}^{\text {exp }}\right)^{2}}
\end{gathered}
$$

Where, $q_{e}^{\exp }$ and $q_{e}^{c a l}$ are the amount of $\mathrm{Cu}(\mathrm{II})$ ions adsorbed (mg.g $\left.{ }^{-1}\right)$ at equilibrium determined from Eq. 2 and the model after using the Solver add-in, respectively; and $q_{e}^{\text {mean }}\left(\mathrm{mg} \cdot \mathrm{g}^{-1}\right)$ is the mean of $q_{e}^{\text {exp }}$ values.

\section{RESULTS AND DISCUSSION}

\section{Characterization}

Fig. 1A shows A. muricata L. seeds while Figs. 1B and 1C show the powder of AMSP and SA-AMSP, respectively. SA-AMSP had a darker color compared to AMSP. The FTIR spectra of AMSP, SA-AMSP, and Cu(II)-loaded SA-AMSP are shown in Fig. 2. The FTIR spectrum of AMSP displayed a number of characteristic bands at 2500 to $3600 \mathrm{~cm}^{-1}, 3286$ $\mathrm{cm}^{-1}, 3008 \mathrm{~cm}^{-1}, 2923 \mathrm{~cm}^{-1}, 1744 \mathrm{~cm}^{-1}, 1639 \mathrm{~cm}^{-1}, 1460 \mathrm{~cm}^{-}$ $1,1020 \mathrm{~cm}^{-1}$, and $722 \mathrm{~cm}^{-1}$, representing the $-\mathrm{COOH}$ group, $-\mathrm{OH}$ and $-\mathrm{NH}$ groups, $=\mathrm{C}-\mathrm{H}$ in aromatic rings, asymmetric $-\mathrm{CH}_{2}$ groups, $\mathrm{COO}^{-}$groups, $-\mathrm{C}=\mathrm{N}$ groups, $\mathrm{C}=\mathrm{C}$ stretching, $\mathrm{C}-\mathrm{O}-\mathrm{C}$, and $\mathrm{C}-\mathrm{H}$ bending (out of plane) of aromatic rings, respectively. The FTIR spectrum of raw AMSP also revealed the abundance of carboxyl, hydroxyl, amino and aromatic groups. The same observations were reported using other adsorbents (Fauzia et al. 2015, Hanafiah et al. 2018). Meanwhile, the SA-AMSP spectrum showed several shifts in the wavenumbers or reduction and increment of the intensity of the peaks. The spectrum of $\mathrm{Cu}(\mathrm{II})$-loaded SA-AMSP displayed almost the same characteristic bands of SA-AMSP. However, the percentage transmittance of some functional at 1744 and $1021 \mathrm{~cm}^{-1}$ had decreased in the $\mathrm{Cu}(\mathrm{II})$-loaded

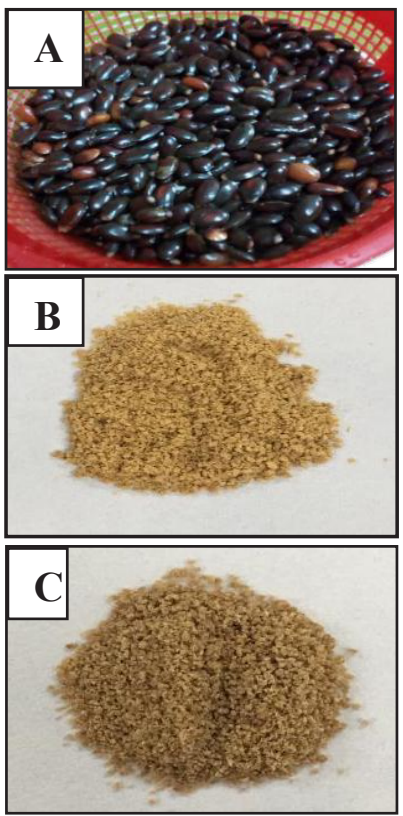

Fig. 1: (A) Raw A. muricata L. seeds, (B) A. muricata L. seed powder washed with hexane (AMSP), and (C) Sulphuric acid-treated A. muricata L. seed powder (SA-AMSP).

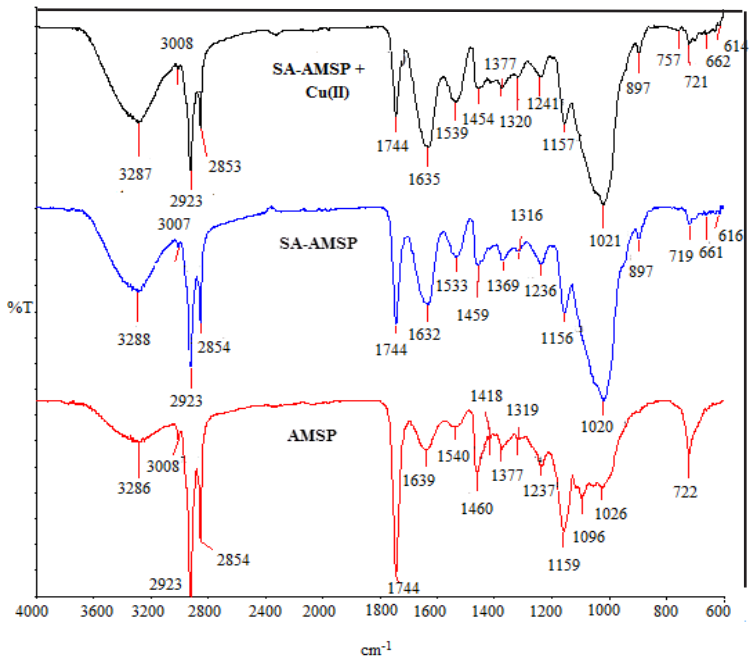

Fig. 2: FTIR spectra of raw AMSP, SA-AMSP (before $\mathrm{Cu}$ (II) adsorption), and $\mathrm{Cu}(\mathrm{II})$-loaded SA-AMSP. 
SA-AMSP. We have observed shifts in wavenumber from 1632 to $1635 \mathrm{~cm}^{-1}, 1533$ to $1539 \mathrm{~cm}^{-1}$, and 1459 to $1454 \mathrm{~cm}^{-1}$. Based on this observation, it can be concluded that the $-\mathrm{COO}^{-},-\mathrm{OH}$, -NH and aromatic rings were the active adsorption sites and that $\mathrm{Cu}$ (II) ions adsorption could occur possibly through the ionic attraction and weak electrostatic attraction.

The SEM and EDX images of AMSP, SA-AMSP, and $\mathrm{Cu}$ (II)-loaded SA-AMSP are shown in Fig. 3 (A to F). Fig. $3 \mathrm{~A}$ shows that the AMSP has an irregular surface, and it lacks porous structure and contains essential metal ions $\left(\mathrm{Mg}^{2+}, \mathrm{Na}^{+}\right.$, and $\left.\mathrm{K}^{+}\right)$on its surface (Fig. 3B). After the acid treatment, there was no obvious difference in the surface structure between SA-AMSP (Fig. 3C) and AMSP. However, the essential metal ions were no longer detected by the EDX due to the dissolution of these ions in the acid (Fig. 3D).

The presence of $\mathrm{Cu}(\mathrm{II})$ ions on SA-AMSP was confirmed by the SEM-EDX images as shown in Fig. 3 (E and F). The $\mathrm{pH}_{\text {slurry }}$ of SA-AMSP was 5.46. The acidic nature of SA-AM$\mathrm{SP}$ was due to the carboxylic acid groups as confirmed by the FTIR spectrum. The $\mathrm{pH}_{\mathrm{PZC}}$ plot is shown in Fig. 4, with a value of 4.50 . At $\mathrm{pH}>\mathrm{pH}_{\mathrm{PZC}}$, the SA-AMSP surface would have a more negative charge, consequently favoring the adsorption of $\mathrm{Cu}$ (II) ions.
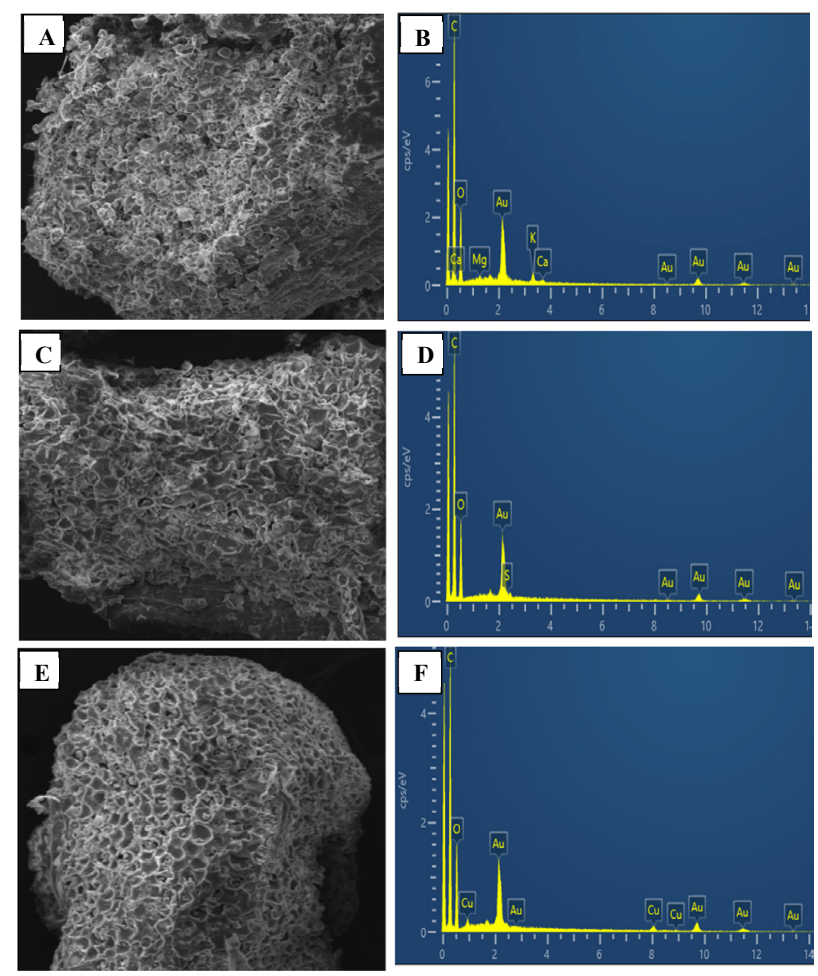

Fig. 3: SEM images (200x magnification) and EDX images of AMSP (A, B), SA-AMSP (C, D) and Cu(II)-loaded SA-AMSP (E, F); respectively.

\section{Batch Adsorption Process}

Effects of $\mathbf{p H}$ and SA-AMSP dosage: The effects of $\mathrm{pH}$ on $\mathrm{Cu}$ (II) uptake are shown in Fig. 5. The amount of $\mathrm{Cu}$ (II) adsorbed on SA-AMSP increased with increasing $\mathrm{pH}$ of the solution from 2 to 6 . At $\mathrm{pH} 2$, the $\mathrm{q}_{\mathrm{e}}$ value was very low due to the strong electrostatic repulsion between the protonated functional groups in SA-AMSP and $\mathrm{Cu}$ (II) ions. However, at $\mathrm{pH}>2$, the deprotonated functional groups such as carboxyl in SA-AMSP increased gradually, and they could readily adsorb $\mathrm{Cu}(\mathrm{II})$ ions. Therefore, the subsequent adsorption experiments were conducted at $\mathrm{pH} 6$.

Fig. 6 shows the effects of SA-AMSP dosage on the adsorption of $\mathrm{Cu}$ (II) ions. The amount of $\mathrm{Cu}$ (II) adsorbed onto the SA-AMSP decreased with increasing SA-AMSP dosage. It may be attributed to the overlapping or aggregation of the adsorption sites at higher adsorbent dosages, consequently reducing the exposed surface area for adsorption of adsorbates (Anbalagan et al. 2016, Mansur et al. 2020). Thus, 0.02 $\mathrm{g}$ of SA-AMSP was chosen for the subsequent kinetics and isotherm experiments.

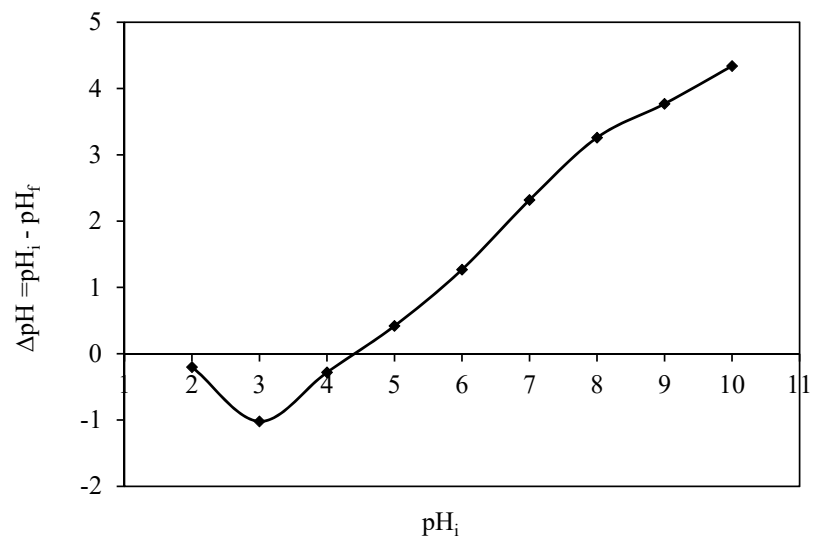

Fig. 4: The $\mathrm{pH}_{\mathrm{PZC}}$ plot for SA-AMSP.

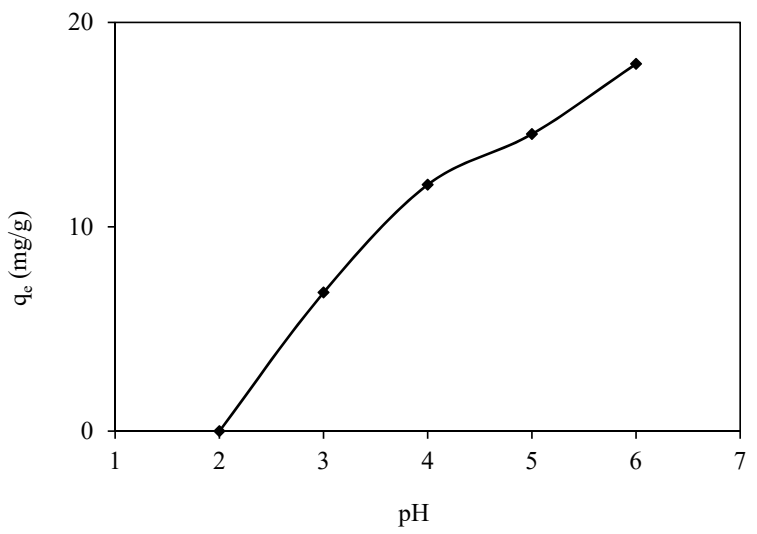

Fig. 5: Effect of solution $\mathrm{pH}$ on $\mathrm{Cu}(\mathrm{II})$ ions adsorption. 
Adsorption kinetics: The changes in the amount of $\mathrm{Cu}$ (II) adsorbed on SA-AMSP as a function of time at two different initial concentrations of $\mathrm{Cu}$ (II) ions (10 and $\left.20 \mathrm{mg} . \mathrm{L}^{-1}\right)$ are shown in Fig. 7. The plots showed three succeeding stages during the adsorption process, including (i) initial rapid adsorption process ( 0 to $5 \mathrm{~min}$ ) where up to 70 and $86 \%$ of $\mathrm{Cu}(\mathrm{II})$ ions were adsorbed onto SA-AMPSP for 10 and 20 $\mathrm{mg} . \mathrm{L}^{-1}$, respectively, due to the high availability of the active adsorption sites; (ii) slow adsorption process (5 to $20 \mathrm{~min}$ ) where only $13 \%$ and $10 \%$ of $\mathrm{Cu}$ (II) ions were adsorbed onto SA-AMPSP for 10 and $20 \mathrm{mg} . \mathrm{L}^{-1}$, respectively, because of the stiff competition among $\mathrm{Cu}$ (II) ions for the remaining active adsorption sites; and (iii) dynamic equilibrium adsorption process (20 to $120 \mathrm{~min}$ ) where only a small change in the amount of $\mathrm{Cu}$ (II) ions adsorbed was observed as the active adsorption sites were fully saturated. Besides that, the amount of $\mathrm{Cu}$ (II) ions adsorbed increased with increasing initial $\mathrm{Cu}$ (II) concentration. This could be due to the higher driving force at higher $\mathrm{Cu}$ (II) ions concentrations, making them capable of overcoming the mass transfer resistance between the adsorbent and liquid phase (Hanafiah et al. 2018).

The adsorption data of Figure 7 were analyzed using the non-linear and linear kinetics models to further investigate the rate of $\mathrm{Cu}(\mathrm{II})$ ions adsorption. The non-linear pseudo-first-order (PFO) and pseudo-second-order (PSO) models were given by Eqs. (5) and (6) (Ho \& McKay 1998), respectively.

$$
\begin{aligned}
& q_{t}=q_{e}\left(1-e^{k_{1} t}\right) \\
& q_{t}=\frac{q_{e}^{2} k_{2} t}{\left(1+k_{2} q_{e} t\right)}
\end{aligned}
$$

The linear PFO and PSO kinetic equations were presented by eqs. (7) and (8), respectively:

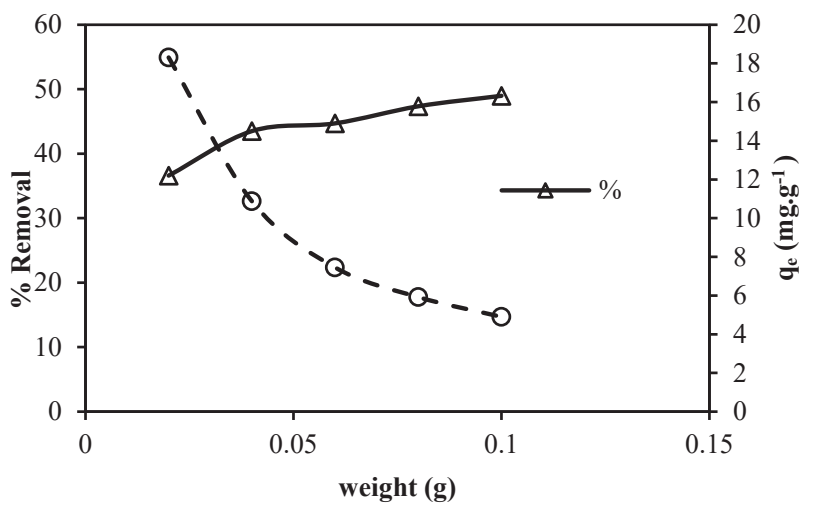

Fig. 6: Effect of SA-AMSP dosage on $\mathrm{Cu}(\mathrm{II})$ ions adsorption.

$$
\begin{gathered}
\log \left(q_{e}-q_{t}\right)=\log q_{e}-\frac{k_{1}}{2.303} t \\
\frac{t}{q_{t}}=\frac{1}{k_{2} q_{e}^{2}}+\frac{1}{q_{e}} t
\end{gathered}
$$

where $q_{\mathrm{e}}$ and $q_{t}$ refer to the amount of $\mathrm{Cu}$ (II) ions adsorbed at equilibrium (mg.g ${ }^{-1}$ ) and at the time, $t$, respectively. The $k_{1}$ and $k_{2}$ represent the overall rate constants of PFO $\left(\mathrm{min}^{-1}\right)$ and PSO (g.mg. min $^{-1}$ ) models. The kinetic parameters obtained from the non-linear and linear equations as well as the $R^{2}$ and $\chi^{2}$ values are reported in Table 1 . For the PFO model, the calculated values of $q_{e}$ did not match the experimental ones while the values of $R^{2}$ were lower and the values of $\chi^{2}$ were higher compared with the PSO model. This indicated the non-validity of the PFO model to explain the kinetics behavior of the adsorption process. A satisfactory agreement was obtained between the calculated and experimental values of $q_{e}$ with the values of $R^{2}$ being close to unity. The $\chi^{2}$ values were much lower, confirming the validity of the PSO to the adsorption process.

Isotherm studies: The adsorption capacity at the equilibrium state $\left(q_{e}, \mathrm{mg}^{-\mathrm{g}^{-1}}\right)$ for SA-AMSP was plotted against the equilibrium concentration of $\mathrm{Cu}(\mathrm{II})$ ions $\left(C_{e}, \mathrm{mg} . \mathrm{L}^{-1}\right)$ as shown in Figure 8 . The equilibrium adsorption capacity increased with the increase in the initial $\mathrm{Cu}$ (II) ions concentration possibly due to the increased rate of mass transfer of adsorbates on the

\begin{tabular}{|c|c|c|c|c|}
\hline Models & & Parameters & $10 \mathrm{mg} \cdot \mathrm{L}^{-1}$ & $20 \mathrm{mg} \cdot \mathrm{L}^{-1}$ \\
\hline \multirow{4}{*}{$\begin{array}{l}\text { Pseu- } \\
\text { do-first } \\
\text { order }\end{array}$} & \multirow{4}{*}{ Non-linear } & $q_{e}^{\exp }\left(\mathrm{mg} \cdot \mathrm{g}^{-1}\right)$ & 12.80 & 22.22 \\
\hline & & $q_{e}^{c a l}\left(\mathrm{mg} \cdot \mathrm{g}^{-1}\right)$ & 12.17 & 20.88 \\
\hline & & $k_{l}\left(\min ^{-1}\right)$ & 0.390 & 0.495 \\
\hline & & $R^{2}$ & 0.749 & 0.348 \\
\hline \multirow{11}{*}{$\begin{array}{l}\text { Pseu- } \\
\text { do-sec- } \\
\text { ond order }\end{array}$} & \multirow{3}{*}{ Linear } & $\chi^{2}$ & 0.062 & 0.206 \\
\hline & & $q_{e}^{\mathrm{cal}}\left(\mathrm{mg} \cdot \mathrm{g}^{-1}\right)$ & 1.36 & 2.59 \\
\hline & & $k_{l}\left(\min ^{-1}\right)$ & 0.004 & 0.008 \\
\hline & \multirow{3}{*}{ Non-linear } & $R^{2}$ & 0.373 & 0.679 \\
\hline & & $q_{e}^{\text {cal }}\left(\mathrm{mg} \cdot \mathrm{g}^{-1}\right)$ & 12.51 & 21.36 \\
\hline & & $k_{2}\left(\right.$ g.mg.min $\left.{ }^{-1}\right)$ & 0.086 & 0.073 \\
\hline & \multirow{5}{*}{ Linear } & $R^{2}$ & 0.922 & 0.626 \\
\hline & & $\chi^{2}$ & 0.019 & 0.117 \\
\hline & & $q_{e}^{c a l}\left(\mathrm{mg} \cdot \mathrm{g}^{-1}\right)$ & 12.74 & 22.27 \\
\hline & & $k_{2}\left(\right.$ g.mg.min $\left.{ }^{-1}\right)$ & 0.050 & 0.022 \\
\hline & & $R^{2}$ & 0.999 & 0.998 \\
\hline
\end{tabular}
adsorbent (Anbalagan et al. 2016). The adsorption isotherm data obtained in Figure 8 were analyzed using the non-linear

Table 1: Kinetic parameters of $\mathrm{Cu}(\mathrm{II})$ ions adsorption on SA-AMSP. 
Langmuir (Langmuir 1918) (Eq. 9) and Freundlich models (Freundlich 1906) (Eq. 10).

$$
\begin{gathered}
q_{e}=\frac{Q_{\max } K_{L} C_{e}}{1+K_{L} C_{e}} \\
q_{e}=K_{F} C_{e}^{1 / n}
\end{gathered}
$$

where $Q_{\max }$ is the theoretical maximum adsorption capacity (mg. $\left.\mathrm{g}^{-1}\right), K_{\mathrm{L}}$ is the Langmuir isotherm constant related to the strength of adsorbent-adsorbate interaction $\left(\mathrm{L} \mathrm{mg}^{-1}\right), K_{\mathrm{F}}$ and $n$ are the Freundlich constants related to the adsorption capacity and intensity, respectively. The values of the Langmuir and Freundlich constants were calculated from the non-linear regression for each model (Table 2).

Fig. 8 shows that the experimental data of the adsorption of the $\mathrm{Cu}$ (II) ions on SA-AMSP had a better fit to the Freundlich model than the Langmuir model. Furthermore, the Freundlich model's strong representation of the experimental data was supported by higher $R^{2}$ and lower $\chi^{2}$ values, both of which are measures of goodness of fit. This indicated the non-homogeneity of active sites on the surface of the SA-AMSP adsorbent. The adsorption capacity of SA-AMSP calculated from the Langmuir model was $187.83 \mathrm{mg} . \mathrm{g}^{-1}$, which recorded a higher capacity compared with the other adsorbents reported in the literature (Table 3). Therefore, SA-AMSP has an excellent potential application to treat wastewater containing $\mathrm{Cu}(\mathrm{II})$ ions.

\section{CONCLUSION}

Sulphuric acid-treated A. muricata $\mathrm{L}$ seeds powder (SA-AM$\mathrm{SP})$ showed an excellent ability to remove $\mathrm{Cu}(\mathrm{II})$ ions from aqueous solutions using the batch mode adsorption technique. Based on the FTIR spectrum of SA-AMSP, the detected functional groups such as carbonyl $(\mathrm{C}=\mathrm{O})$, hydroxyl

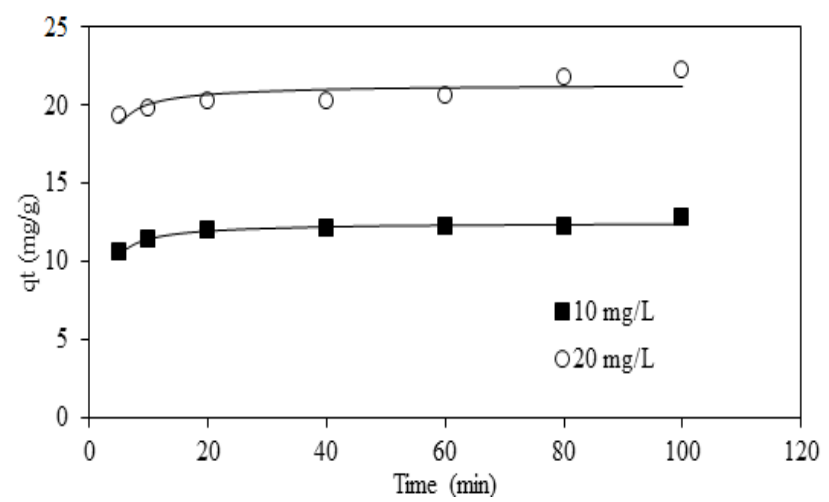

Fig. 7: Effects of initial concentration and contact time on $\mathrm{Cu}(\mathrm{II})$ ions adsorption.
$(-\mathrm{OH})$, the carboxylic acid $(-\mathrm{COOH})$, amino $\left(-\mathrm{NH}_{2}\right)$, ether (C-O-C), and aromatic groups acted as the active sites for the $\mathrm{Cu}$ (II) ions. The attachment of $\mathrm{Cu}$ (II) ions on SA-AMSP was confirmed by the EDX images. The maximum adsorption capacity was found to be $187.8 \mathrm{mg} \cdot \mathrm{g}^{-1}$, suggesting that the SA-AMSP could be a low-cost and environmentally friendly adsorbent for treating $\mathrm{Cu}(\mathrm{II})$-containing wastewaters.

\section{REFERENCES}

Afroze, S. and Sen, T.K. 2018. A Review on heavy metal ions and dye adsorption from water by agricultural solid waste adsorbents. Water Air Soil Pollut., 229: 225.

Al Zabadi, H., Sayeh, G. and Jodeh, S. 2018. Environmental exposure assessment of cadmium, lead, copper, and zinc in different Palestinian canned foods. Agric. Food Sec., 7: 50.

Anaya Esparza, L.M. and Montalvo-González, E. 2020. Bioactive compounds of soursop (Annona muricata L.) fruit. In: Murthy, H. and Bapat, V. (eds.), Bioactive Compounds in Underutilized Fruits and Nuts. Reference Series in Phytochemistry. Springer, Cham, pp. 1-13.

Table 2: Langmuir and Freundlich parameters for $\mathrm{Cu}(\mathrm{II})$ ions adsorption onto SA-AMSP at $302 \mathrm{~K}$.

\begin{tabular}{|ll|}
\hline Isotherm models & \\
\hline Non-linear Langmuir model & \\
$Q_{\max }\left(\mathrm{mg}^{-1}{ }^{-1}\right)$ & 187.8 \\
$K_{L},\left(\mathrm{~L} \cdot \mathrm{mg}^{-1}\right)$ & 0.010 \\
$R^{2}$ & 0.997 \\
$\chi^{2}$ & 0.234 \\
Non-linear Freundlich model & \\
$K_{F}\left(\mathrm{~L} \cdot \mathrm{mg}^{-1}\right)$ & 2.570 \\
$N$ & 0.820 \\
$R^{2}$ & 0.999 \\
$\chi^{2}$ & 0.038 \\
\hline
\end{tabular}

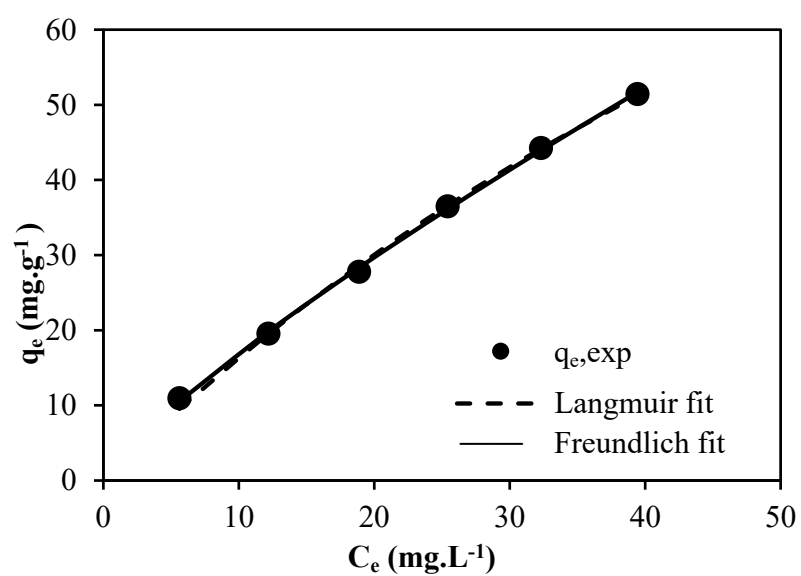

Fig. 8: Langmuir and Freundlich isotherm plots for $\mathrm{Cu}(\mathrm{II})$ ions adsorption onto SA-AMSP. 
Table 3: Maximum adsorption capacities of $\mathrm{Cu}(\mathrm{II})$ ions by different adsorbents.

\begin{tabular}{|c|c|c|c|c|c|}
\hline Adsorbent & $Q_{\max }\left(\mathrm{mg} \cdot \mathrm{g}^{-1}\right)$ & $\mathrm{pH}$ & $\begin{array}{l}\text { Temperature } \\
(\mathrm{K})\end{array}$ & $\begin{array}{l}\text { Equilibrium } \\
\text { time }\end{array}$ & References \\
\hline $\mathrm{H}_{2} \mathrm{SO}_{4}$-treated A. muricata $\mathrm{L}$. seed powder & 187.83 & 6.0 & 302 & 40 & Present study \\
\hline Bentonite supported nanoscale zero-valent iron & 52.63 & 4.0 & 298 & 50 & Zhang and Qiu (2019) \\
\hline $\mathrm{NaOH}$-treated- rice husk & 48.84 & NA & 280 & 30 & Zafar et al. (2020) \\
\hline $\mathrm{Na}^{+}$-treated Pisha Sandstone & 21.37 & 5.0 & 303 & 60 & Wang et al. (2020) \\
\hline Pisha Sandstone & 19.49 & 5.0 & 303 & 60 & Wang et al. (2020) \\
\hline $\mathrm{NaOH}$-treated rubber leaf powder & 14.97 & 4.0 & 300 & 60 & Wan Ngah and Hanafiah (2008) \\
\hline Sulphuric acid-treated peanut husk & 10.15 & 4.0 & 298 & 60 & Li et al. (2007) \\
\hline Sawdust & 6.58 & 4.0 & 298 & 60 & Li et al. (2007) \\
\hline Montmorillonite-biochar composite & 6.92 & 4.0 & 303 & 30 & Cai et al. (2019) \\
\hline $\mathrm{HNO}_{3}$-treated $A$. muricata $\mathrm{L}$. seed powder & 5.54 & 4.0 & NA & 60 & Kurniawan et al. (2014) \\
\hline
\end{tabular}

NA: Not available

Anbalagan, K., Kumar, P.S. and Karthikeyan, R. 2016. Adsorption of toxic $\mathrm{Cr}(\mathrm{VI})$ ions from aqueous solution by sulphuric acid-modified Strychnos potatorum seeds in batch and column studies. Desal. Water Treat., 57(27): 12585-12607.

Cai, Y., Du, Y., Wang, Y., Song, J., Liu, B., Zhang, C. and Qiu, M. 2019. Adsorption of copper ions in aqueous solution by montmorillonite-biochar composite. Nat. Environ. Pollut. Technol., 18(4): 1201-1209.

Cairdir, Z., Furqani, F., Zein, R. and Munaf, E. 2015. Utilization of Annona muricata $\mathrm{L}$. seeds as potential adsorbents for the removal of rhodamine B from aqueous solution. J. Chem. Pharm. Res., 7(4): 879-888.

Fauzia, S., Furqani, F., Zein R. and Munaf, E. 2015. Adsorption and reaction kinetics of tartrazine by using Annona muricata L seeds. J. Chem. Pharm. Res., 7(1): 573-582.

Freundlich, H.M.F. 1906. About the in solutions. J. Phys. Chem., 57: 385-470.

Hanafiah, M.A.K.M., Mohd Jamalduin, S.Z., Khalid, K. and Ibrahim, S. 2018. Methylene blue adsorption on Aloe vera rind powder: Kinetics, isotherm, and mechanisms. Nat. Environ. Pollut. Technol., 17(14): 1055-1064.

Ho, Y.S. and McKay, G. 1998. Comparison of chemisorption kinetic models applied to pollutant removal on various sorbents. Process Saf. Environ. Prot., 76: 332-340.

Karimi, S., Yaraki, M.T. and Karri, R.R. 2019. A comprehensive review of the adsorption mechanisms and factors influencing the adsorption process from the perspective of bioethanol dehydration. Renew. Sust. Energ. Rev., 107: 535-553.

Kurniawan M.I., Abdullah, Z., Rahmadani A., Zein R. and Munaf, E. 2014. Isotherm and kinetic modeling of $\mathrm{Pb}(\mathrm{II})$ and $\mathrm{Cu}$ (II) uptake by Annona muricata L. seeds. Asian J. Chem., 26(12): 3588-3594.

Langmuir, I. 1918. The adsorption of gases on plane surfaces of glass, mica, and platinum. J. Am. Chem. Soc., 40: 1361-1403
Li, Q., Zai, J., Zhang, W., Wang, M. and Zhou, J. 2007. Kinetic studies of adsorption of $\mathrm{Pb}$ (II), $\mathrm{Cr}$ (III), and $\mathrm{Cu}$ (II) from aqueous solution by sawdust and modified peanut husk. J. Hazard Mater., 141: $163-167$.

Mansur, N.F., Hanafiah, M.A.K.M. and Ismail, M. 2020. Pb(II) adsorption onto urea treated Leucaena leucocephala leaf powder: Characterization, kinetics, and isotherm studies. Nat. Environ. Pollut. Technol., 19(11): 311-318.

Menzes, E.G.T., Oliviera, E.R., Carvalho, G.R., Guimaraes, I.C., and Queiroz, F. 2019. Assessment of chemical, nutritional and bioactive properties of Annona crassiflora and Annona muricata wastes. Food Sci. Technol., 39(2): 662-672.

Oboh, O.I. and Aluyor, E.O. 2008. The removal of heavy metal ions from aqueous solutions using soursop seeds as biosorbent. Afr. J. Biotechno., 7(24): 4508-4511.

Sawant, T.P. and Dongre, R.S. 2014. Bio-chemical compositional analysis of Annona muricata: A miracle fruit's review. Int. J. Univers. Pharm. Bio Sci., 3(2): 82-104.

Wan Ngah, W.S. and Hanafiah, M.A.K.M. 2008. Biosorption of copper ions from dilute aqueous solutions on base treated rubber (Hevea brasiliensis) leaves powder: kinetics, isotherm, and biosorption mechanisms. J. Environ. Sci., 20: 1168-1176.

Wang, X., Cui, Y., Peng, Q., Fan, C., Zhang, Z. and Zhang, X. 2020. Removal of $\mathrm{Cd}(\mathrm{II})$ and $\mathrm{Cu}(\mathrm{II})$ from aqueous solution by Na+-Modified Pisha Sandstone. J. Chem., 28: 579.

Zafar, S., Khan, M.I., Lashari, M.H., Khraisheh, M., Almomani, F., Mirza, M.L., and Khalid, N. 2020. Removal of copper ions from aqueous solution using $\mathrm{NaOH}$-treated rice husk. Emerg. Mater., 3: 857-870.

Zhang, J. and Qiu, M. 2019. Adsorption kinetics and isotherms of copper ion in aqueous solution by bentonite supported nanoscale zero-valent iron. Nat. Environ. Pollut. Technol., 18(1): 269-274. 